\title{
Virtual Simulation Training Course Construction Based on Irai Platform
}

\author{
Wei Zhao; Mengying Liu*; Liu Han \\ Tianjin Key Laboratory of High Speed Cutting \&Precision Machining \\ TUTE \\ Tianjin, China \\ zhaowei@tju.edu.cn
}

\begin{abstract}
A new training course is presented to construct the physical environment and control object, and use the external real electric circuit to control the virtual complex mechanical structure based on Irai platform. The training course system adheres to the student-oriented, aims to cultivate ability of learning, vocation and communication for students, which is taking full use of the advantages of simulation technology and provide a platform for experiment, training and innovative business competition. The courses of mechanical and electrical integration have been developed in this platform including machine tool control, PLC experiment or training, CNC machine equipment Maintenance experiments or training, other production development and so on.
\end{abstract}

Keywords-Virtual reality technology; virtual simulation laboratory; PLC experiment; Irai; mechanical and electrical integration

\section{INTRODUCTION}

In most of the institutions of science and technology at home and abroad, all kinds of training courses take the important role because of their practical, operation and other advantages. However, the main problems faced by the current training courses are high cost of training equipment, less numbers of training equipment and training equipment can not be followed the rapid development of the enterprise. In addition, the integration of theoretical courses and practice is not high and the integration of the mechanism, control, computer and other courses is low, which are the current main problems.

Virtual simulation technology is a highly integrated product of professional subjects and contemporary information technology. In this paper, Irai software is used as a platform to construct a realistic training environment and control object, and use external real electrical lines to control the virtual complex mechanical structure and effectively solve above problems. In order to cultivate the new century college students with the goal of developing a new century, practical training projects have been developed based on Irai software and related experimental instructions, ppt, exercises, video and other teaching materials have also been done according to the requirements of the training course syllabus, which not only to provide teaching ideas, methods and equipment for Irai software experimental training courses, but also to propose a

Liu Mengying is corresponding author (e-mail: 358413334@qq.com)). feasible solutions to a series of problems.

\section{Application Status OF ViRTUal Simulation RESOURCES}

Virtual reality (VR), also known as "spiritual environment", "virtual environment", also is a computer systems to create and experience the virtual world [1]. Virtual environment is generated by the computer and electronic technology, which is to create an immersive experience for user by perception.

Virtual reality technology can turn the project large-scale datum into a visual object, so which also has a wide range of applications in the equipment design and manufacturing. As early as 1984, NASA developed a virtual planetary detection system, the Mars probe back to the data into three-dimensional virtual world. And in 1986 the concept of virtual workstations was put forward. In 1989, the founder of the United States VPL officially proposed VR technology [2]. Since the 1990s, with the development of computer software and hardware technology, the development of VR technology has been greatly promoted.

Our government has also pointed out the development direction of relevant fields in the recent macro policy [3]. The Ministry of Education in the "on the comprehensive improvement of higher vocational education teaching a number of opinions" put forward to make full use of modern information technology, the development of virtual factories, virtual workshop, virtual technology, virtual experiment [4]. In addition, in the major lectures of the country and the multimedia course contest competitions, virtual simulation software winning ratio increased year by year.

Recently, in the domestic market Yulong, Swan simulation software and most of the CAM-based simulation software are used widely. But the software is only in the computer virtual rendering image data, only the virtual machine and model can be controlled. The virtual simulation system based on IRAI can combine the virtual world with the real world and make it more effective in teaching.

\section{IRAI SOFTWARE INTRODUCTION}

Irai software is a $3 \mathrm{D}$ modeling software and simulation software. With the help of external 3D modeling software, we can quickly create a three-dimensional interactive simulation model of the automation system [5]. With Irai simulation 
software, designers of industrial equipment and automation systems are able to test their products in a realistic and interactive $3 \mathrm{D}$ virtual environment and monitor the behavior of analog devices in real time [6]. By connecting a 3D simulation model with an external controller, such as a PLC or an embedded virtual controller, Irai can reproduce the operation of the device or machine in the real world in a completely virtual environment [7]. The specific process of use is shown in Figure 1.

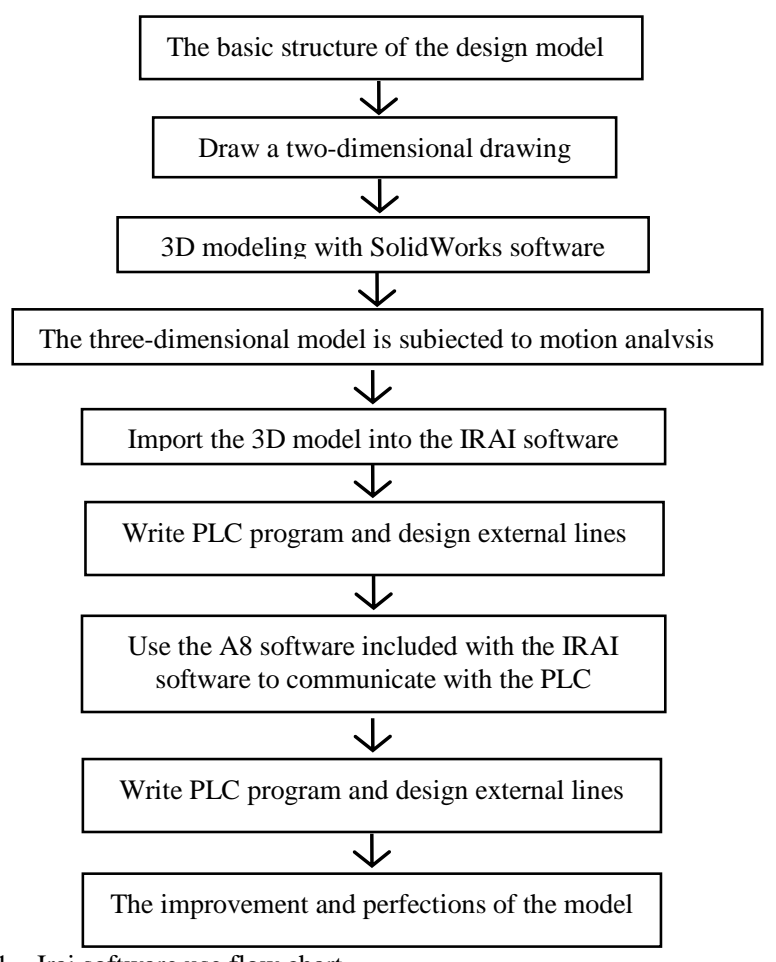

Fig. 1. Irai software use flow chart

Irai software is the main software Virtual Universe Pro V2, this software is mainly three-dimensional modeling software Solidworks and other three-dimensional modeling software to establish a three-dimensional model introduced in the PC provided by the environment and platform, the threedimensional model the simulation of the specific movement to verify the correctness of the three-dimensional model design. Thus avoiding the actual production of the movement of the machine can not predict the security risks, and the authenticity of the software so that the operator feel immersive, getting best results.

Irai software comes with the A8 software, this software can be external to the actual PLC and electrical lines and PC virtual platform in the three-dimensional model linked to the use of external PLC and electrical lines to control the PC internal three-dimensional model Perform exercise simulation and program preparation exercises. A8 software in which played an important role in the communication bridge, the virtual and reality linked together [8].

\section{3D MODEL BUILD AND SETUP}

Virtual platform control object is the actual equipment, 3D images, so the first step is to build the platform 3D model. SolidWorks software was used for three-dimensional modeling, include drawing parts and assembling to get the following model of ordinary lathe, as is shown in Figure 2.

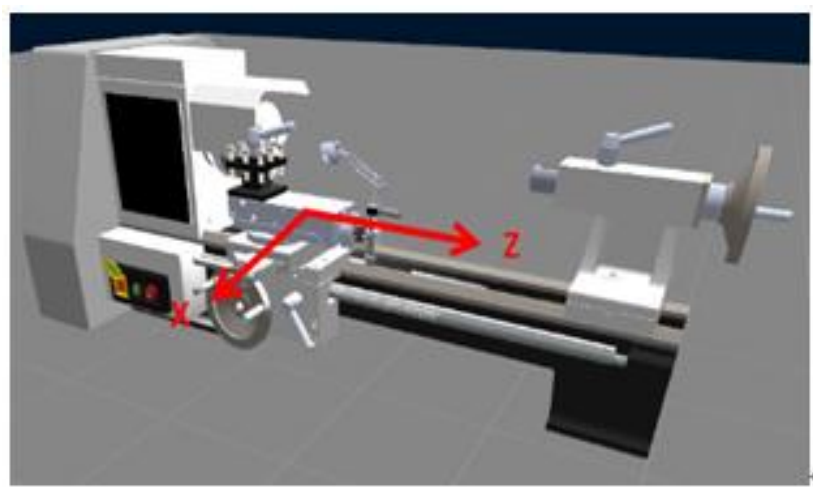

Fig. 2. General lathe 3D model

Since the main body of the simulation platform is VU Pro, the model is needed to import into VU Pro software. After the initial assembly, each part is not directly related to each other, which can be free to move, and have no physical properties and athletic ability, needing to set them further.

In the virtual model to determine a central matrix, the other parts set to its sub-level, and then they complete the action defined to the center of the matrix, the central matrix can be achieved as a whole, the child associated with the movement. The movement carried out, including movement along the $\mathrm{Z}$ axis and along the $X$ axis. These movements are then connected to the movement of the $\mathrm{X}$-axis set by the respective interfaces in the PLC controller and the movement of the Zaxis. The correct establishment of the central matrix will make the whole system in line with the logical relationship between the movements, greatly reducing the difficulty of setting. Set the logical relationship shown in Figure 3 below.

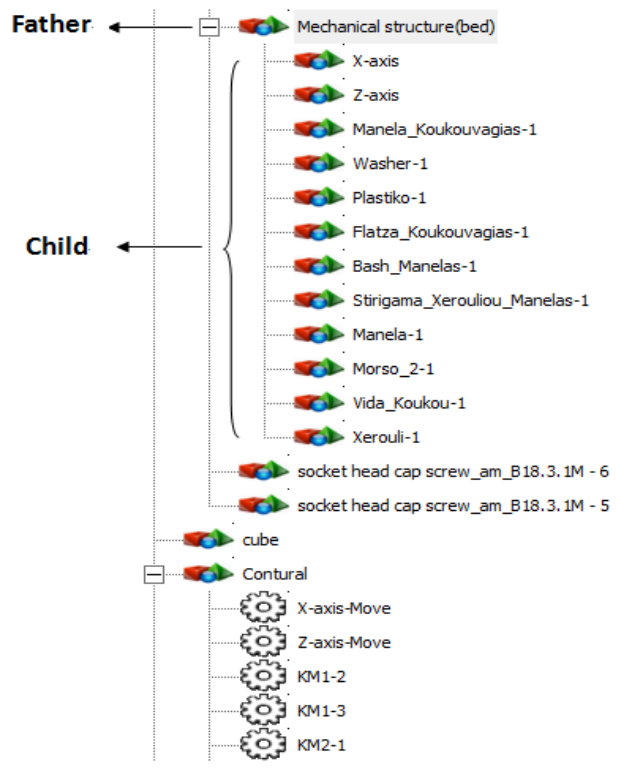

Fig. 3. Motion logic diagram 
After the movement relationship is set up, it is necessary to establish a communication project between PLC and VU Pro software through A8 software, and assign the register address to the corresponding action to complete the communication and carry out the simulation experiment.

\section{TEACHING RESOURCES DEVELOPMENT OF VIRTUAL SIMULATION TRAINING ROOM}

According to the principle from shallow to deep, three sets of models have been developed based on Irai platform, including machine control model, production line control model and other models.

As shown in table 1:

TABLE I MODEL SUMMARY CHART

\begin{tabular}{|c|c|c|}
\hline Machine control model & $\begin{array}{c}\text { Production line control } \\
\text { model }\end{array}$ & Other models \\
\hline Vertical milling machine & Feeding production line & Automatic garage \\
\hline Surface Grinder & Conveyor sorting & Responders \\
\hline Lathe & Conveyor model & LED \\
\hline $\begin{array}{c}\text { Horizontal bring } \\
\text { machine }\end{array}$ & Manipulator \\
\hline $\begin{array}{c}\text { Rocker drill } \\
\text { Processing center knife } \\
\text { library }\end{array}$ & $\begin{array}{c}\text { Automated manufacturing } \\
\text { line }\end{array}$ & Traffic light \\
\hline
\end{tabular}

In this actual and virtual platform, the model is built based on OBE education concept. First, determine to achieve ability by the application of the model. And then according to the ability to determine the elements of knowledge, skills, and then set a detailed lesson plans and exercises. Then according to the effect to revise plans and optimize goals, which forms a closedloop training model achieving optimized teaching result. The training process adopts the method of rationalization, virtual and real integration, and combines the basic theory and practical operation of machinery control and computer to solve the practical problems of the various courses and the lack of effective convergence. The platform can not only serve as a mechanical, automation professional classroom experimental training platform, but also as a second classroom, provide the rich practical space and train students to solve complex problems.

The ordinary lathe experiment is taken to explain the implementation of the specific OBE model.

\section{A. The establishment of lesson plans}

First of all, according to the purpose of training, the establishment of experimental quality training capacity matrix, listed the following training courses outline, as is shown in table 2:

TABLE II CURRICULUM OUTLINE

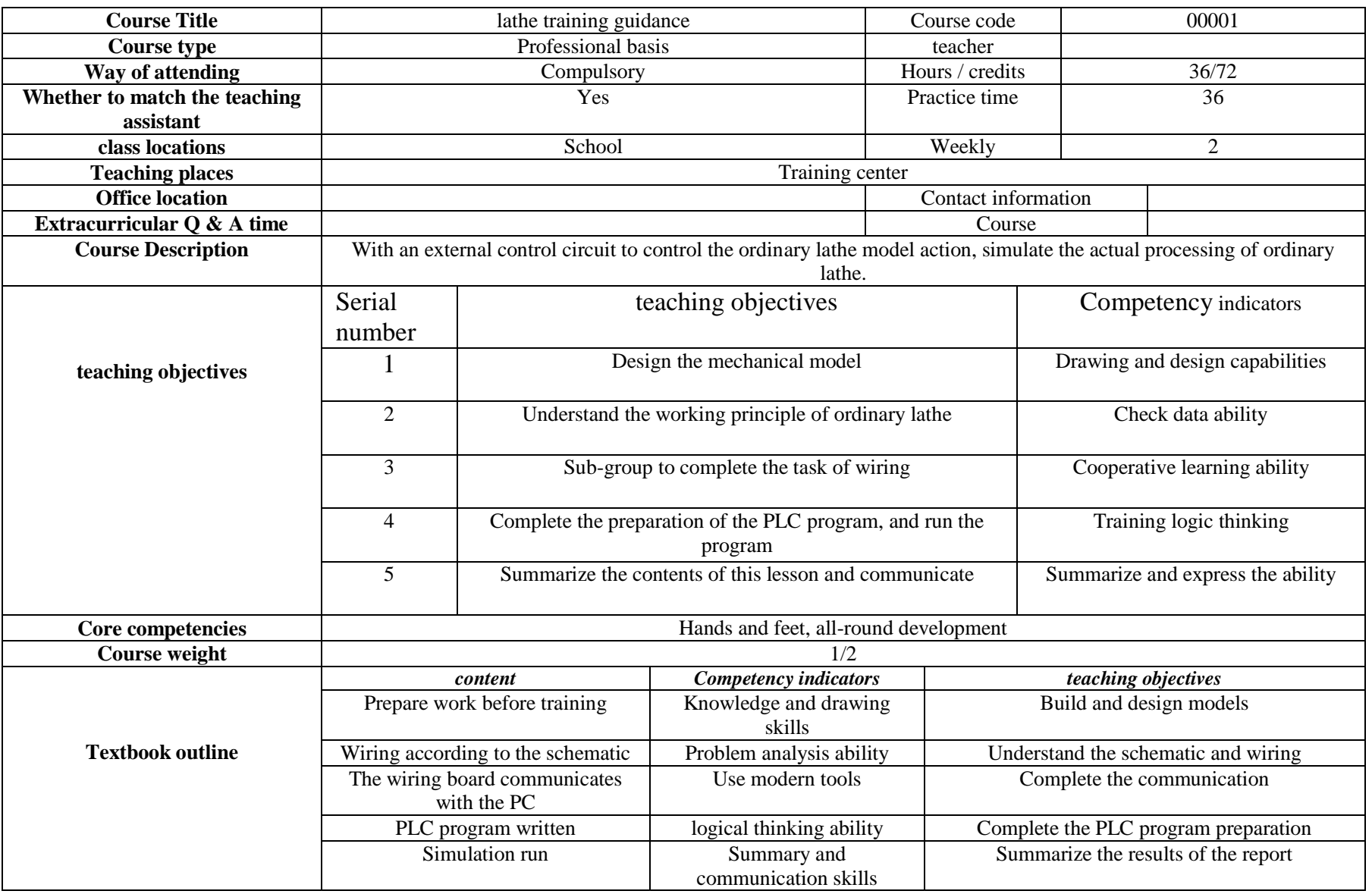




\begin{tabular}{|c|c|c|c|c|}
\hline \multicolumn{5}{|c|}{ Table II, cont. } \\
\hline Teaching methods & \multicolumn{4}{|l|}{ Practice } \\
\hline \multirow{4}{*}{ Evaluation method } & Grade item & Evaluation method & Detail item & Description \\
\hline & Model design & Classroom assessment & 30 & $\begin{array}{l}\text { According to the model design rationality to the } \\
\text { points }\end{array}$ \\
\hline & Line construction & Site evaluation & 30 & Measure whether the line is connected \\
\hline & $\begin{array}{l}\text { PLC } \\
\text { programming }\end{array}$ & Model of the operation & 40 & Whether the program design is reasonable \\
\hline \multirow{7}{*}{ Course schedule } & weekly & Unit content & ability & teaching objectives \\
\hline & 1 & $\begin{array}{l}\text { Horizontal boring } \\
\text { machine }\end{array}$ & $\begin{array}{l}\text { Practical } \\
\text { ability }\end{array}$ & Control of Horizontal Boring Machine with PLC \\
\hline & 2 & lathe & $\begin{array}{l}\text { Practical } \\
\text { ability }\end{array}$ & Control of ordinary lathe movement with PLC \\
\hline & 3 & Rocker drill & $\begin{array}{l}\text { Practical } \\
\text { ability }\end{array}$ & Control the rocker movement with PLC \\
\hline & 4 & Milling machine & $\begin{array}{l}\text { Practical } \\
\text { ability }\end{array}$ & Control milling machine movement with PLC \\
\hline & 5 & $\begin{array}{l}\text { Processing center knife } \\
\text { library }\end{array}$ & $\begin{array}{l}\text { Practical } \\
\text { ability }\end{array}$ & Control the magazine movement with PLC \\
\hline & 6 & Surface Grinder & $\begin{array}{l}\text { Practical } \\
\text { ability }\end{array}$ & Control the surface grinder movement with PLC \\
\hline Teaching materials & \multicolumn{4}{|c|}{ Based on IRAI software training guidance } \\
\hline Reference books & \multicolumn{4}{|c|}{ IRAI software development tutorial } \\
\hline After the course & \multicolumn{4}{|c|}{ Simulation of automated production line simulation } \\
\hline Education resources & \multicolumn{4}{|c|}{ Virtual simulation training platform } \\
\hline Attentive notes & \multicolumn{4}{|l|}{ Theory and practice } \\
\hline Reflection after class & & & & \\
\hline
\end{tabular}

Secondly, according to the ability matrix, the design of the program, including experimental purposes, experimental steps, experimental content diagram and control process. Through the study of the experiment, students can make the mechanical and electrical integration control more in-depth understanding and exploration, to achieve the goals set by the above objectives.

\section{B. The composition of the exercises}

With the various experiments, targeted design of different after-school exercises. Exercises are mainly composed of three parts, namely the theoretical part, the practice part and the content expansion. The theoretical part mainly focuses on the practice of the principals involved in the training and the theoretical content used in the training, and deepens the understanding of the conceptual principles put forward in the theoretical course. The practical part includes summarizing and summarizing the problems encountered in the training process and the training, and mainly the practical ability of the students and the ability to summarize the induction. Content expansion is mainly for the training content, creatively put forward a new design or planning, inspire students thinking, and develop students' creativity and imagination.

\section{VIRTUAL SIMULATION EXPERIMENT CASE}

Ordinary lathe is taken as an example to describe the realization process of virtual simulation training. In order to make the virtual training teaching more close to the real training environment, with the traditional mechanical and electrical integration experiment, virtual training operation model and the real machine size, line wiring and programming exactly the same, and the same working environment, the experimental interface as is shown in Figure 4. The important mechanical design parts of the machine are analyzed by exercise feasibility to ensure the practicability of their movement.

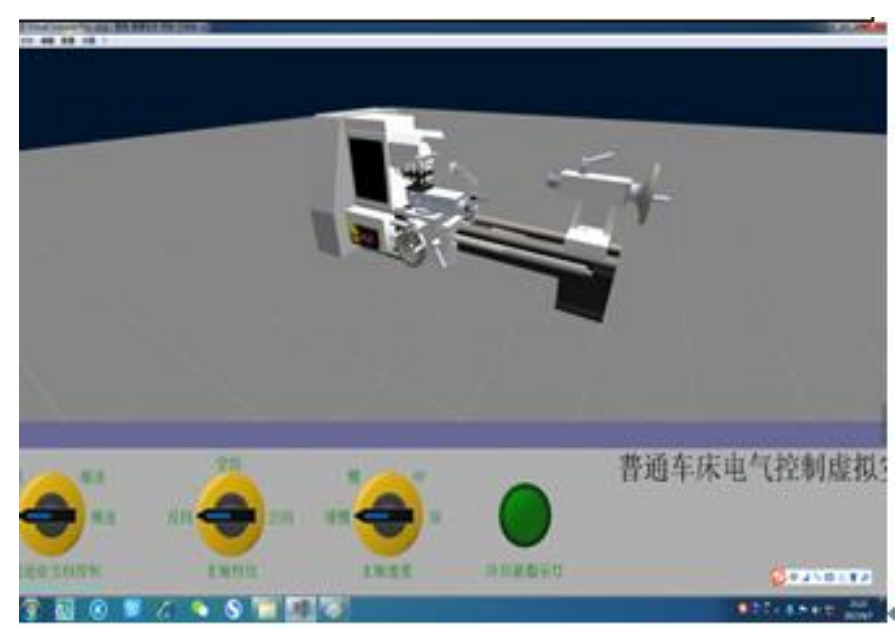

Fig. 4. Common lathe experimental interface

Virtual training began, first for learners to provide training instructions to learn and practice the main function of the platform, as shown in Figure5 below.

Learners can first through the training instructions and wiring board pictures for training before the preview, and then through the training instructions of the experimental steps to carry out the corresponding experiments. In accordance with the instructions, first of all, understand the purpose of learning and learning goals, according to the prompt preparation of training equipment and electronic components. Then according to the requirements of the experimental bench for the corresponding wiring work. After the wiring is completed, if the project needs PLC program preparation, then:

- According to the experimental content, in Siemens V4.0 STEP 7 MicroWIN SP9 programming environment, the 
preparation of ladder program, after the simulation debugging (virtual to virtual).

- Start A8 software to IRAI and PLC to communicate, connect the various ports.

- Simulation operation (real virtual).
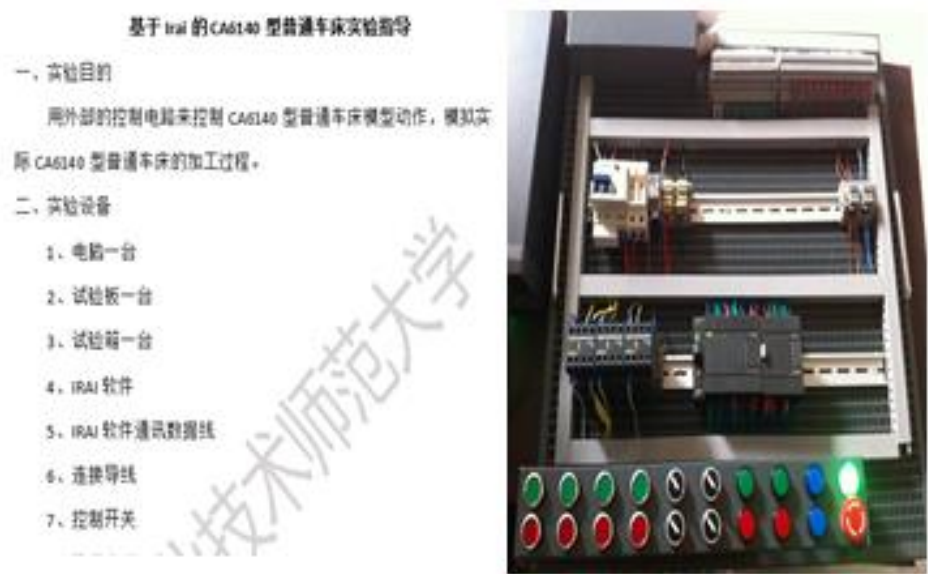

Fig. 5. Training instructions and experimental wiring board

\section{CONCLUSION}

At present, the virtual simulation teaching technology has been developed, is to lead the university engineering training and vocational training in the vocational education to the modernization of the new direction. In this paper, we have developed a set of electromechanical integration of virtual and real simulation training system with Irai platform, which effectively solved the difficulties in teaching and learning of mechanical and electrical disengagement, expanded the teaching resources, saved the experimental funds and space, and realized the "green" training. The platform can also be used for innovative design, prototype development, mechanical and electrical integration debugging to provide an efficient platform.

\section{REFERENCES}

[1] Fang Chengxin. On the exploration of experimental resources sharing in colleges and universities [J] .Experimental Research and Exploration, 2014, 31 (8): 260-262.

[2] China Engineering Certification Association. Engineering Education Certification Standard .2015.

[3] Virtual Universe Pro V2 User Manual [M]. Beijing .2013.

[4] Ministry of Education, Ministry of Finance. Notice on Approving the Construction Unit of the National Experimental Teaching Demonstration Center in 2015: Teaching Letter [2015] No. 21 [Z] .2015.

[5] Xu Jin. 2013 national virtual simulation experiment teaching center construction summary and 2014 recommendations [J]. Laboratory Research and Exploration, 2014, 33 (8): 1-5.

[6] Zhou Shijie, Ji Jiacheng, Wang Hua. Virtual simulation experiment teaching center construction and practice [J]. Computer Education, 2015 (9): 5-11.

[7] Gong Hanyue, Luo Qingsheng, Han Baoling, et al. Research and design of virtual control platform for crawler robot [J]. Computer Measurement and Control, 2012 (3): 694-696,701.

[8] Richter D. Infusing an interdisciplinary automation experience in engineering technology education[C]/Proceedings of the 2013 American Society for Engineering Education Annual Conference \& Exposition .Honolulu, 2013. 